\title{
PENGARUH KEPEMIMPINAN TERHADAP KINERJA KARYAWAN PADA PT. KIRANA MITRA ABADI TANGERANG
}

\author{
Muhamad Guruh ${ }^{1}$, Iman Syatoto ${ }^{2}$, Abdul Razak ${ }^{3}$ \\ Fakultas Ekonomi, Universitas Pamulang \\ Email: dosen02256@unpam.ac.id
}

\begin{abstract}
Purpose. This study aims to determine how much influence leadership has on employee performance at PT. Kirana Mitraabadi Tangerang where the independent variable studied was leadership while the dependent variable was employee performance.

Methods. The method used in this research is descriptive quantitative method, while data processing uses several tests, namely validity test, reliability test, correlation coefficient test, simple linear regression test, determination coefficient test ( $R$ Square) and $t$-test with data processing using SPSS version. 25. The population and sample studied were employees of PT. Kirana Mitraabadi Tangerang as many as 50 employees using a saturated sample.

Findings. The results of the research and calculations show that the value of the correlation calculation results is 0.948 which indicates that there is a very strong relationship between leadership and employee performance. Through a simple linear regression test, the linear regression equation is obtained $=1.959+0.951 X$, meaning that if the variable $X$ is increased by one unit, the variable $\hat{Y}$ tends to increase by 0.951 at the constant 1.959. The coefficient of determination obtained a value of 0.899, which means that leadership affects the performance of $89.90 \%$, while the remaining $10.10 \%$ is influenced by other factors not examined such as motivation, discipline, compensation and so on. Meanwhile, from the results of the tcount test, it is obtained 20.667 while $t$ table is 2.011, then tcount $>$ ttable means that $\mathrm{HO}$ is rejected and $\mathrm{Ha}$ is accepted with the understanding that there is a significant influence between leadership $(X)$ on employee performance $(Y)$.
\end{abstract}

Implication. Leaders are expected to provide more examples of positive attitudes at work in order to encourage employees to work well for the progress of the company.

Keywords. Leadership and Employee Performance.

\begin{abstract}
ABSTRAK
Tujuan. Penelitian ini bertujuan untuk mengetahui seberapa besar pengaruh kepemimpinan terhadap kinerja karyawan pada PT. Kirana Mitraabadi Tangerang dimana variabel independen yang diteliti adalah kepemimpinan sedangkan variabel dependennya adalah Kinerja Karyawan.
\end{abstract}

Metode. Metode yang digunakan pada penelitian ini ialah metode kuantitatif deskriptif, sedangkan pengolahan data menggunakan beberapa pengujian yaitu uji validitas, uji reliabilitas, uji koefisien korelasi, uji regresi linier sederhana, uji koefisien determinasi (R Square) dan uji-t dengan pengolahan data menggunakan SPSS versi 25. Populasi dan sampel yang diteliti adalah karyawan PT. Kirana Mitraabadi Tangerang sebanyak 50 karyawan dengan menggunakan sampel jenuh.

Hasil. Hasil penelitian dan perhitungan menunjukkan bahwa nilai Dari perhitungan korelasi didapatkan hasil 0,948 yang menunjukkan bahwa terdapat hubungan yang sangat 
kuat antara kepemimpinan dengan kinerja karyawan. Melalui uji regresi linier sederhana didapatkan persamaan regresi linier $\widehat{Y}=1,959+0,951 \mathrm{X}$, artinya apabila variabel X ditingkatkan satu satuan, maka variabel $\hat{Y}$ cenderung meningkat sebesar 0,951 pada konstanta 1,959. Pada koefisien determinasi diperoleh nilai sebesar 0,899 yang artinya kepemimpinan mempengaruhi kinerja sebesar 89,90\%, sedangkan sisanya 10,10\% dipengaruhi oleh faktor lain yang tidak diteliti seperti motivasi, kedisiplinan, kompensasi dan lain sebagainya. Sedangkan dari hasil pengujian $t_{\text {hitung }}$ diperoleh 20,667 sedangkan $t_{\text {tabel }}$ sebesar 2,011, maka $t_{\text {hitung }}>t_{\text {tabel }}$ artinya $\mathrm{H}_{0}$ ditolak dan $\mathrm{H}_{\mathrm{a}}$ diterima dengan pengertian bahwa terdapat pengaruh yang signifikan antara Kepemimpinan $(\mathrm{X})$ terhadap Kinerja Karyawan (Y).

Implikasi. Pemimpin diharapkan untuk lebih memberikan contoh sikap positif dalam bekerja agar dapat memberikan dorongan kepada karyawan untuk dapat bekerja dengan baik demi kemajuan perusahaan.

Kata Kunci. Kepemimpinan dan Kinerja Karyawan.

\section{Pendahuluan}

Masalah sumber daya manusia masih menjadi sorotan dan tumpuan bagi perusahaan untuk tetap dapat bertahan pada persaingan di era globalisasi saat ini. Sumber daya manusia mempunyai peran utama dalam setiap kegiatan perusahaan. Walaupun telah didukung dengan sarana dan prasarana serta sumber dana yang telah mencukupi, tetapi tanpa dukungan sumber daya manusia yang handal kegiatan perusahaan tidak akan terselesaikan dengan baik. Hal ini menunjukan bahwa sumber daya manusia merupakan kunci pokok yang harus di perhatikan dengan sangat baik.

PT. Kirana Mitraabadi adalah sebuah perusahaan produsen Petroleum Wax atau lilin parafin yang berbasis di indonesia. Sejak Oktober 2011, PT. Kirana Mitraabadi memiliki kemitraan eksklusif dengan Perusahaan minyak dan gas milik negara yaitu pertamina untuk pembuatan dan pemasaran lilin parafin minyak bumi. Namun tujuan PT. Kirana Mitraabadi belum sepenuhnya optimal, salah satunya adanya permasalahan yang berkaitan dengan hasil produksi yang dicapai belum sepenuhnya sesuai dengan target yang telah ditetapkan. Yang dibuktika melalui data tabel pencaiapan target hasil produksi periode Bulan Januari sampai dengan Bulan Desember 2018 sebagai berikut.

Tabel 1. Data Pencapaian Hasil Target Produksi Periode Januari - Bulan Desember 2018

\begin{tabular}{|c|l|c|c|c|}
\hline No & \multicolumn{1}{|c|}{ Bulan } & Target & Hasil & Persentase \\
\hline 1 & Januari & 400 Ton & 380 Ton & $95 \%$ \\
\hline 2 & Februari & 400 Ton & 376 Ton & $94 \%$ \\
\hline 3 & Maret & 400 Ton & 400 Ton & $100 \%$ \\
\hline 4 & April & 400 Ton & 350 Ton & $87,5 \%$ \\
\hline 5 & Mei & 400 Ton & 300 Ton & $75 \%$ \\
\hline 6 & Juni & 400 Ton & 320 Ton & $80 \%$ \\
\hline 7 & Juli & 400 Ton & 420 Ton & $105 \%$ \\
\hline 8 & Agustus & 400 Ton & 350 Ton & $87,5 \%$ \\
\hline 9 & September & 400 Ton & 377 Ton & $94,25 \%$ \\
\hline 10 & Oktober & 400 Ton & 380 Ton & $95 \%$ \\
\hline 11 & November & 400 Ton & 393 Ton & $98,25 \%$ \\
\hline 12 & Desember & 400 Ton & 389 Ton & $97,25 \%$ \\
\hline
\end{tabular}

Sumber : PT. Kirana Mitraabadi Tangerang, 2020 
Dari data tabel diatas dapat disimpulkan bahwa hasil produksi yang dihasilkan perbulannya masih banyak yang belum mencapai target. Dari salah satu masalah diatas penulis mengajukan kuesioner Pra-penelitian dengan menggunakan 3 variabel kemungkinan penyebab masalah yang terjadi yaitu kepemimpinan, stres kerja dan insentif kepada 20 orang karyawan atau responden yang terdapat di PT. Kirana Mitraabadi, berikut jawaban hasil kuesioner dari 20 responden.

\section{Tabel 2. Hasil Jawaban Responden Pra-Penelitian}

\begin{tabular}{|c|l|c|c|}
\hline No & \multicolumn{1}{|c|}{ Pernyataan } & Setuju & Tidak Setuju \\
\hline 1 & $\begin{array}{l}\text { Pemimpin kurang memotivasi karyawan } \\
\text { dalam melaksanakan pekerjaan. }\end{array}$ & 15 & 5 \\
\hline 2 & $\begin{array}{l}\text { Pembagian tugas yang diberikan pemimpin } \\
\text { kurang sesuai dengan keahlian yang } \\
\text { dimiliki karyawan. }\end{array}$ & 17 & 7 \\
\hline 3 & $\begin{array}{l}\text { Pemimpin masih kurang tegas dalam } \\
\text { pengambilan keputusan. }\end{array}$ & 13 & 15 \\
\hline 4 & $\begin{array}{l}\text { Beban tugas yang diberikan dirasa cukup } \\
\text { berat. }\end{array}$ & 5 & 13 \\
\hline 5 & $\begin{array}{l}\text { Waktu bekerja berlebihan hingga membuat } \\
\text { karyawan merasa kelelahan. }\end{array}$ & 7 & 11 \\
\hline 6 & $\begin{array}{l}\text { Target yang banyak membuat karyawan } \\
\text { merasa stres. }\end{array}$ & 11 & 14 \\
\hline 7 & $\begin{array}{l}\text { Insentif yang diberikan tidak sesuai dengan } \\
\text { beban pekerjaan. }\end{array}$ & 9 & 10 \\
\hline 8 & $\begin{array}{l}\text { Pemberian insentif pada karyawan dirasa } \\
\text { tidak adil. }\end{array}$ & 6 & $\begin{array}{l}\text { Kurangnya insentif yang diberikan } \\
\text { membuat karyawan malas dalam bekerja. }\end{array}$ \\
\hline
\end{tabular}

Sumber : Pra Survey

Dari hasil jawaban responden Pra-penelitian diatas dapat disimpulkan bahwa salah satu penyebab yang paling dominan pada masalah menurunnya kuantitas atau hasil produksi sehingga tidak mencapai target adalah dari variabel kepemimpinan yakni sikap pemimpin yang ada di PT. Kirana Mitraabadi yang ditunjukkan dari banyaknya responden yang setuju terhadap pernyataan mengenai sikap pemimpinnya, sehingga berdampak pada menurunnya kinerja karyawan pada perusahaan.

Berdasarkan pemaparan di atas maka penulis tertarik melakukan penelitian dengan judul "Pengaruh Kepemimpinan Terhadap Kinerja Karyawan Pada PT. Kirana Mitraabadi Tangerang".

\section{Kajian Pustaka dan Hipotesis}

Kepemimpinan. Menurut Hasibuan (2014:170) Kepemimpinan (leadership) adalah cara seorang pemimpin mempengaruhi perilaku bawahan, agar mau bekerjasama dan bekerja secara produktif untuk mencapai tujuan organisasi. Sedangkan pemimpin seseorang dengan wewenang kepemimpinannya mengarahkan bawahannya untuk mengerjakan sebagian dari pekerjaannya dalam mencapai tujuan. Sedangkan menurut Veithzal Rivai (2014:2) menyatakan bahwa definisi kepemimpinan secara luas adalah "meliputi proses mempengaruhi dalam menentukan tujuan organisasi, memotivasi prilaku pengikut untuk mencapai tujuan, mempengaruhi perubahan-perubahan mengenai peristiwa-peristiwa para pengikutnya, pengorganisasian dan aktivitas-aktivitas untuk mencapai sasaran, memelihara hubungan kerjasama dan kerja kelompok, perolehan dukungan dan kerjasama dari kerjasama dari orangorang diluar kelompok atau organisasi". 
Indikator adalah alat ukur berupa statistik yang dapat menunjukan perbandingan, kecenderungan atau perkembangan. Indikator kepemimpinan yang akan dijadikan pedoman dalam kuesioner di penelitian yang akan di jadikan pedoman kuesioner dipenelitian ini menurut Hasibuan (2014:199), yaitu keteladanan, kewibawaan, pendelegasian tugas, pengambilan keputusan dan motivasi:

1) Keteladanan. Sebagai instruktur yang baik terhadap bawahannya dengan menjadi pimpinan bijaksana yang memungkinkan setiap bawahan semakin pintar dan profesional dalam melaksanakan tugas.

2) Kewibawaan. Pemimpin dapat membantu atau menolong bawahan mengataasi masalah yang dihadapinya dalam pelaksanaan tugas yang di bebankan kepada bawahan tersebut.

3) Pendelegasian Tugas. Pemimpin yang bijaksana harus mendelegasikan sebagian tugas dan wewenang kepada bawahannya.pendelegasian ini di perlukan untuk meminimalisir hambatan.

4) Pengambilan Keputusan Keberhasilan seorang pemimpin sangat di tentukan oleh keterampilan mengambil keputusan disaat kritis sekalipun.

5) Motivasi. Motivasi memberikan daya untuk maju lebih baik lagi, tanpa motivasi apapun yang di kerjakan akan menjadi beban. Pemimpin perlu mengadakan rapat dan memimpin dengan mengikutsertakan seluruh potensi yang terkait melaksanakan rencana tersebut.

Kinerja Karyawan. Menurut Wibowo (2012:7), kinerja adalah proses dari rencana yang telah disusun. Proses kinerja dilakukan oleh sumber daya manusia yang memiliki kemampuan, kompetensi, motivasi dan kepentingan. Sedangkan menurut Mangkunegara (2015:67) kinerja (prestasi kerja) adalah hasil kerja secara kualitas dan kuantitas yang dicapai oleh seorang pegawai dalam melaksanakan tugasnya sesuai dengan tanggung jawab yang diberikan kepadanya.

Menurut Mangkunegara (2015:67) Kinerja (prestasi kerja) adalah hasil kerja secara kualitas dan kuantitas yang dicapai oleh seorang pegawai dalam melaksanakan tugasnya sesuai dengan tanggung jawab yang diberikan kepadanya. Indikator-indikator kinerja karyawan adalah sebagai berikut:

1) Kuantitas Pekerjaan berhubungan dengan volume pekerjaan dan produktivitas kerja yang di hasilkan oleh karyawan dalam kurun waktu tertentu.

2) Kualitas Pekerjaan berhubungan dengan pertimbangan ketelitian, presisi, kerapian, dan kelengkapan didalam menangani tugas-tugas yang ada dalam organisasi.

3) Inisiatif adalah kemampuan karyawan untuk bertindak melebihi yang dibutuhkan atau dituntut oleh pekerjaan. Inisiatif berkenaan dengan pertimbangan kemandirian dan fleksibilitas berfikir.

4) Tanggungjawab merupakan hal penting yang harus dimiliki oleh karyawan karena berkenaan dalam melaksanakan segala tugas dan pekerjaan yang telah diberikan oleh pimpinan.

5) Kerjasama merupakan pekerjaan individu yang di kerjakan bersama-sama dengan tujuan agar pekerjaan tersebut menjadi lebih ringan, kerjasama berkaitan dengan pertimbangan kemampuan untuk bekerjasama dengan orang lain.

Berdasarkan penjelasan di atas, maka dapat dibuat sebuah gambaran kerangka pemikiran dalam penelitian ini: 


\begin{tabular}{|c|c|}
\hline $\begin{array}{l}\text { Kepemimpinan }(X) \\
\text { 1. Keteladanan } \\
\text { 2. Kewibawaan } \\
\text { 3. Pendelegasian } \\
\text { Tugas } \\
\text { 4. Pengambilan } \\
\quad \text { Keputusan } \\
\text { 5. Motivasi } \\
\text { Sumber: Hasibuan } \\
(2012: 199)\end{array}$ & $\begin{array}{l}\text { Kinerja Karyawan }(\mathrm{Y}) \\
\text { 1. Kuantitas } \\
\quad \text { Pekerjaan } \\
\text { 2. Kualitas } \\
\quad \text { Pekerjaan } \\
\text { 3. Inisiatif } \\
\text { 4. Tanggungjawab } \\
\text { 5. Kerjasama } \\
\text { Sumber: } \\
\text { Mangkunegara } \\
(2015: 67)\end{array}$ \\
\hline
\end{tabular}

\section{Gambar 2. Model Penelitian}

\section{Hipotesis}

$\mathrm{H}_{\mathrm{o}}$ : Diduga tidak terdapat pengaruh yang signifikan antara kepemimpinan terhadap kinerja karyawan pada PT. Kirana Mitraabadi Tangerang.

$\mathrm{H}_{\mathrm{a}}$ : Diduga terdapat pengaruh yang signifikan antara kepemimpinan terhadap kinerja karyawan pada PT. Kirana Mitraabadi Tangerang

\section{Metode Penelitian}

Pada penelitian ini penulis melakukan penelitian di PT. Kirana Mitraabadi Tangerang yang beralamat di Kawasan Industri Milenium Blok A12 No.1, Jalan Pemda Tigaraksa Baru, Budi Mulya, Cikupa Tangerang Banten. Jenis penelitian yang digunakan dalam penelitian ini adalah penelitian dengan menggunakan pendekatan kuantitatif yang datanya berupa data hasil angket (questioner). Menurut Sugiyono (2017:8) Penelitian kuantitatif adalah penelitian yang berlandaskan pada filsafat postivisme, digunakan untuk meneliti pada populasi atau sampel tertentu, pengumpulan data menggunakan instrumen penelitian, analisis data bersifat kuantitatif statistik, dengan tujuan untuk menguji hipotesis yang telah ditetapkan. Penelitian kuantitatif ini dituntut untuk menggunakan banyak angka, mulai dari pengumpulan data, penafsiran terhadap data tersebut, serta penampilan dari data tersebut.

Populasi dalam penelitian ini yaitu seluruh karyawan dibagian produksi sebanyak 50 orang karyawan. Teknik pengambilan sampel yang digunakan dalam penelitian ini adalah teknik sampel jenuh. Seperti yang dikemukakan oleh Sugiyono (2017:96) sampel jenuh adalah teknik penentuan sampel bila semua anggota populasi digunakan sebagai sampel. Istilah lain sampel jenuh adalah sensus, dimana semua anggota populasi dijadikan sampel karena jumlah karyawan di PT. Kirana Mitraabadi yang berjumlah 50 orang. Teknik analisis data dengan menggunakan Uji validitas, uji reliabilitas, uji regresi linier sederhana, serta uji hipotesis.

Tabel 3. Operasional Variabel Penelitian

\begin{tabular}{|c|c|c|c|}
\hline $\begin{array}{c}\text { Variabel } \\
\text { Penelitian }\end{array}$ & Definisi Operasional & Indikator & Butir \\
\hline $\begin{array}{c}\text { Kepemimpinan } \\
(\mathrm{X})\end{array}$ & 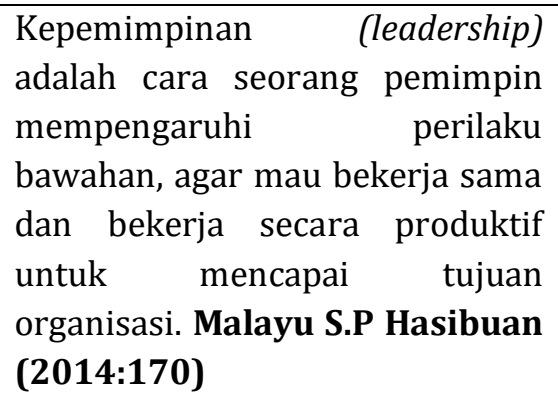 & $\begin{array}{l}\text { 1. Keteladanan } \\
\text { 2. Kewibawaan } \\
\text { 3. Pendelegasian Tugas } \\
\text { 4. Pengambilan Keputusan } \\
\text { 5. Motivasi }\end{array}$ & $\begin{array}{l}1 \& 2 \\
3 \& 4 \\
5 \& 6 \\
7 \& 8 \\
9 \& 10\end{array}$ \\
\hline
\end{tabular}




\begin{tabular}{|c|l|l|c|}
\hline $\begin{array}{c}\text { Variabel } \\
\text { Penelitian }\end{array}$ & \multicolumn{1}{|c|}{ Definisi Operasional } & \multicolumn{1}{|c|}{ Indikator } & Butir \\
\hline \multirow{3}{*}{ Kinerja } & Kinerja (prestasi kerja) adalah & 1. Kuantitas Pekerjaan & 1 \& 2 \\
Karyawan (Y) & hasil kerja secara kualitas dan & 2. Kualitas Pekerjaan & 3 \& 4 \\
& $\begin{array}{l}\text { kuantitas yang dicapai oleh } \\
\text { seorang pegawai dalam } \\
\text { melaksanakan tugasnya sesuai } \\
\text { dengan tanggung jawab yang } \\
\text { diberikan kepadanya. } \\
\text { Mangkunegara (2015:67) }\end{array}$ & 4. Tanggungjawab & 7 \& 8 \\
& & \\
\end{tabular}

\section{Hasil Penelitian dan Pembahasan Uji Validitas}

Tabel 4. Hasil Uji Validitas

\begin{tabular}{|c|c|c|c|c|}
\hline No & Pernyataan & Rhitung & Rtabel & Keterangan \\
\hline \multicolumn{5}{|l|}{ Kepemimpinan } \\
\hline 1 & Butir Pernyataan 1 & 0,811 & 0,284 & Valid \\
\hline 2 & Butir Pernyataan 2 & 0,467 & 0,284 & Valid \\
\hline 3 & Butir Pernyataan 3 & 0,836 & 0,284 & Valid \\
\hline 4 & Butir Pernyataan 4 & 0,615 & 0,284 & Valid \\
\hline 5 & Butir Pernyataan 5 & 0,517 & 0,284 & Valid \\
\hline 6 & Butir Pernyataan 6 & 0,513 & 0,284 & Valid \\
\hline 7 & Butir Pernyataan 7 & 0,672 & 0,284 & Valid \\
\hline 8 & Butir Pernyataan 8 & 0,814 & 0,284 & Valid \\
\hline 9 & Butir Pernyataan 9 & 0,584 & 0,284 & Valid \\
\hline 10 & Butir Pernyataan 10 & 0,703 & 0,284 & Valid \\
\hline Kinerja Karyawan & \multicolumn{5}{|l|}{} \\
\hline 1 & Butir Pernyataan 1 & 0,814 & 0,284 & Valid \\
\hline 2 & Butir Pernyataan 2 & 0,440 & 0,284 & Valid \\
\hline 3 & Butir Pernyataan 3 & 0,669 & 0,284 & Valid \\
\hline 4 & Butir Pernyataan 4 & 0,509 & 0,284 & Valid \\
\hline 5 & Butir Pernyataan 5 & 0,524 & 0,284 & Valid \\
\hline 6 & Butir Pernyataan 6 & 0,473 & 0,284 & Valid \\
\hline 7 & Butir Pernyataan 7 & 0,433 & 0,284 & Valid \\
\hline 8 & Butir Pernyataan 8 & 0,539 & 0,284 & Valid \\
\hline 9 & Butir Pernyataan 9 & 0,691 & 0,284 & Valid \\
\hline 10 & Butir Pernyataan 10 & 0,606 & 0,284 & Valid \\
\hline
\end{tabular}

Sumber : Data diolah (2020)

Berdasarkan tabel diatas dapat dilihat bahwa untuk masing-masing pernyataan pada variabel Kepemimpinan $(\mathrm{X})$ dan kinerja karyawan $(\mathrm{Y}) 10$ pernyataan terbukti valid, karena nilai $r_{\text {hitung }}>r_{\text {tabel }}$ yang ada untuk $n=50$, dengan ketentuan df $(n-2)$ maka $50-2=48$, yaitu 0,284 . 
Tabel 5. Hasil Uji Reliabilitas

\begin{tabular}{|c|c|c|}
\hline Variabel & Cronchbach's Alpha & Keterangan \\
\hline Kepemimpinan & 0,851 & Reliabel \\
\hline Kinerja Karyawan & 0,777 & Reliabel \\
\hline
\end{tabular}

Sumber : Data diolah (2020)

Berdasarkan tabel tersebut di atas, diketahui bahwa semua variabel (kepemimpinan dan kinerja karyawan) memiliki nilai cronbachalpha lebih besar $(>)$ dari 0,60 maka dapat disimpulkan kuesioner variabel dalam penelitian ini adalah reliabel dan dapat dilanjutkan pada analisis berikutnya (analisis Regresi).

\section{Uji Koefisien Korelasi}

Tabel 6. Hasil Uji Koefisien Korelasi Model Summary

\begin{tabular}{|c|c|c|c|c|}
\hline Model & $\mathrm{R}$ & $\mathrm{R}$ Square & $\begin{array}{c}\text { Adjusted R } \\
\text { Square }\end{array}$ & $\begin{array}{c}\text { Std. Error of the } \\
\text { Estimate }\end{array}$ \\
\hline 1 &, $615^{\mathrm{a}}$ &, 378 &, 365 & 3,501 \\
\hline
\end{tabular}

a. Predictors: (Constant), Kepemimpinan

Sumber : Data diolah (2020)

Berdasarkan tabel diatas dapat dilihat hasil yang diperoleh bahwa koefisien korelasinya adalah sebesar 0,615. Nilai ini menunjukkan bahwa hubungan antara variabel kepemimpinan (X) dengan variabel kinerja karyawan (Y) adalah kuat.

\section{Analisis Regresi Linier Sederhana}

Tabel 7. Regresi Linier Sederhana

Coefficients ${ }^{\mathrm{a}}$

\begin{tabular}{|c|l|r|r|r|r|r|}
\hline \multicolumn{2}{|c|}{ Model } & \multicolumn{2}{|c|}{$\begin{array}{c}\text { Unstandardized } \\
\text { Coefficients }\end{array}$} & $\begin{array}{c}\text { Standardized } \\
\text { Coefficients }\end{array}$ & \multirow{2}{*}{ t } & \multirow{2}{*}{ Sig. } \\
\cline { 3 - 6 } \multicolumn{2}{|c|}{} & \multicolumn{1}{|c|}{ B } & Std. Error & \multicolumn{1}{|c|}{ Beta } & & \\
\hline 1 & (Constant) & 24,637 & 3,587 & & 6,868 & 0,00 \\
\cline { 2 - 6 } & Kepemimpinan & 0,461 & 0,085 & 0,615 & 5,399 & 0,00 \\
\hline
\end{tabular}

Sumber : Data diolah (2020)

Berdasarkan hasil perhitungan tersebut maka dapat diperoleh persamaan regresi linear sederhana sebagai berikut : $Y=24,637+0,461$ X. Artinya Nilai konstanta sebesar 24,637 menunjukkan bahwa jika variabel kepemimpinan (X) tidak ada atau sama dengan nol, maka kinerja kinerja karyawan $(\mathrm{Y})$ bernilai 24,637. Nilai koefisien regresi variabel kepemimpinan (X) terhadap variabel kinerja karyawan (Y) adalah sebesar 0,461. Hal ini berarti jika kepemimpinan (X) naik 1 satuan maka akan meningkatkan kinerja karyawan sebesar 0,461.

\section{Koefisien Determinasi}

Tabel 8. Hasil Koefisien Determinasi Model Summary

\begin{tabular}{|c|c|c|c|c|}
\hline Model & $\mathrm{R}$ & R Square & $\begin{array}{c}\text { Adjusted R } \\
\text { Square }\end{array}$ & $\begin{array}{c}\text { Std. Error of the } \\
\text { Estimate }\end{array}$ \\
\hline 1 &, $615^{\mathrm{a}}$ &, 378 &, 365 & 3,501 \\
\hline
\end{tabular}

a. Predictors: (Constant), Kepemimpinan

Sumber : Data diolah (2020)

Berdasarkan tabel diatas yakni model summary yang menghasilkan nilai $R$ Square atau koefisien determinasi sebesar 0,378 atau 37,80\%. Hal ini menunjukkan bahwa variabel kepemimpinan mempunyai kontribusi pengaruh dan juga hubungan terhadap kinerja 
karyawan sebesar $37,80 \%$, sedangkan sisanya sebesar $62,20 \%$ dipengaruhi oleh faktor-faktor lainnya yang tidak diteliti dalam penelitian ini.

\section{Uji Hipotesis}

Tabel 9. Hasil Uji t

Coefficients ${ }^{\mathbf{a}}$

\begin{tabular}{|c|l|r|r|r|r|r|}
\hline \multicolumn{2}{|c|}{ Model } & \multicolumn{2}{|c|}{$\begin{array}{c}\text { Unstandardized } \\
\text { Coefficients }\end{array}$} & $\begin{array}{c}\text { Standardized } \\
\text { Coefficients }\end{array}$ & \multirow{2}{*}{ t } & \multirow{2}{*}{ Sig. } \\
\cline { 3 - 6 } & \multicolumn{1}{|c|}{ B } & Std. Error & Beta & & \\
\hline 1 & (Constant) & 24,637 & 3,587 & & 6,868 & 0,00 \\
\cline { 2 - 6 } & Kepemimpinan & 0,461 & 0,085 & 0,615 & 5,399 & 0,00 \\
\hline
\end{tabular}

Sumber : Data diolah (2020)

Dari hasil penelitian pada tabel koefisien regresi variabel kepemimpinan (X) sebesar 0,461 dengan nilai signifikan sebesar 0,000 dan $t_{\text {hitung }}$ sebesar 5,399. Adapun nilai signifikan $0,000<0,05$ dan nilai $t_{\text {hitung }} 5,399>t_{\text {tabel }} 2,011$. Sehingga dapat disimpulkan bahwa kepemimpinan berpengaruh positif dan signifikan terhadap kinerja karyawan pada PT. Kirana Mitraabadi Tangerang. Maka dapat diambil keputusan $\mathrm{H}_{0}$ ditolak dan $\mathrm{H}_{\mathrm{a}}$ diterima, artinya Terdapat pengaruh yang signifikan antara kepemimpinan terhadap kinerja karyawan pada PT. Kirana Mitraabadi Tangerang.

\section{Kesimpulan}

Dari hasil penelitian pengaruh kepemimpinan terhadap kinerja karyawan pada PT. Kirana Mitraabadi Tangerang, penulis menyimpulkan adanya pengaruh yang positif dan signifikan antara kepemimpinan terhadap kinerja karyawan, hal ini didasarkan dari hasil perhitungan analisis regresi linier sederhana yang dihasilkan adalah $Y=24,637+0,461 \mathrm{X}$, hal ini berarti jika kepemimpinan (X) naik 1 satuan maka akan meningkatkan kinerja karyawan (Y) sebesar 0,461. Dan koefisien korelasi yang didapat sebesar 0,615 menunjukkan bahwa terdapat hubungan yang kuat antara kepemimpinan dan kinerja karyawan, sedangkan koefisien determinasi kepemimpinan (X) terhadap kinerja karyawan $(\mathrm{Y})$ sebesar 37,80\% dan sisanya sebesar $62,20 \%$ dipengaruhi oleh faktor lain yang tidak diteliti seperti motivasi, kedisiplinan, kompensasi yang diberikan dan lainnya. Dan dari hasil uji hipotesis diperoleh $t_{\text {hitung }}(5,399)>t_{\text {tabel }}(2,011)$ pada taraf $5 \%$, hal ini menunjukkan bahwa kepemimpinan berpengaruh positif dan signifikan terhadap kinerja karyawan PT. Kirana Mitraabadi Tangerang.

\section{Daftar Pustaka}

Abdullah, M Ma'ruf. (2014) "Manajemen dan Evaluasi Kinerja Karyawan". Aswaja Pressindo. Yogyakarta.

Danang, Sunyoto. (2013). "Metodologi Penelitian Akuntansi”. PT Refika Aditama Anggota Ikapi. Bandung.

Getol, Gunadi. (2012). "Management Miracle Series: Accepted Leader". PT. Elex Media Komputindo Kelompok Gramedia. Jakarta.

Hani, T Handoko. (2012). "Manajemen Personalia dan Sumber Daya Manusia". Edisi Kedua,BPFE. Yogyakarta.

Hasibuan, Malayu. (2014). "Manajemen Sumber Daya Manusia". Edisi Revisi, PT Bumi Aksara. Jakarta.

Kartini, Kartono. (2011). "Pemimpin dan Kepemimpinan". PT Rajawali grafindo Persada. Jakarta. 
Mangkunegara, Anwar Prabu. (2015). "Sumber Daya Manusia Perusahaan". Cetakan Kedua Belas, Remaja Rosdakarya. Bandung.

Prawirosentono, Suyadi. (2013). "Manajemen Sumber Daya Manusia Kebijakan Kinerja Karyawan". BPFE. Yogyakarta.

Riniwati, Harsuko. (2011). "Mendongkrak Motivasi dan Kinerja: Pendekatan Pemberdayaan Sumber Daya Manusia". UB Press. Malang.

Rivai, Veithzal. (2014). "Manajemen Sumber Daya Manusia untuk Perusahaan". Edisi Keenam, PT Raja Grafindo. Jakarta.

Rivai, Veithzal dan Deddy Mulyadi. (2012). "Kepemimpinan dan Perilaku Organisasi". Edisi Ketiga, PT Raja Grafindo. Jakarta.

Safroni, Ladzi. (2012). "Manajemen dan Reformasi Pelayanan Publik dalam Konteks Birokrasi Indonesia". Aditya Media Publishing. Surabaya.

Sedarmayanti. (2013). "Manajemen Sumber Daya Manusia”. Refika Aditama. Bandung.

Siagian, Sondang P. (2014). “Manajemen Sumber Daya Manusia”. PT Bumi Aksara. Jakarta.

Silalahi, Ulber. (2012). "Metode Penelitian Sosial”. Refika Aditama. Bandung.

Sugiyono. (2017). “Metode Penelitian Kuantitatif, Kualitatif, dan R\&D”. CV Alfabeta. Bandung.

Wibowo. (2012). "Manajemen Kinerja”. Raja Grafindo Persada. Jakarta. 